\title{
Motivasi wisatawan mengunjungi desa wisata Blimbingsari, Jembrana, Bali
}

\author{
I Gusti Bagus Rai Utama dan I Wayan Ruspendi Junaedi \\ Universitas Dhyana Pura Bali \\ Email: raiutama@undhirabali.ac.id
}

\begin{abstract}
This study is about tourist's motivation to visit Blimbingsari Village, Jembrana, in West Bali. This study has aim to determine the push factors, and pulls factors to visit Blimbingsari Village. The respondents are 100 people. Based on their genders, there are $46 \%$ male and $54 \%$ female. Domestic tourists are $46 \%$, and $28 \%$ Australian, and the other nationalities. Student visitors are $28 \%, 18 \%$ are retired, and $64 \%$ are workers in various sectors. The result of structural equation modelling (SEM) analysis indicates that the push factor correlation has not significantly affect to the tourist visiting to the Tourism Village of Blimbingsari. The correlations between attractiveness factors have significantly affect to the tourist visiting to the Tourism Village of Blimbingsari. Therefore, the management of Blimbingsari Tourism Village maybe directed to highlight the attractiveness of the village e.g. the uniqueness of the village, the village community activities, culture or traditions, natural beauty of the village, the availability of lodging, culinary, public facilities, visitor center, distance from the airport, the distance from the capital, and availability of transport.
\end{abstract}

Keyword: Agro Tourism, Tourism Village, push factor, pull factor, tourist attraction, tourist activity

\footnotetext{
Abstrak

Penelitian ini adalah tentang motivasi wisatawan yang mendorong, dan yang menarik wisatawan berkunjung ke Desa Wisata Blimbingsari, Jembrana di Bali Barat. Tujuannya adalah untuk menentukan faktor-faktor yang mendorong, dan yang menarik wisatawan berkunjung ke Desa Wisata Blimbingsari. Responden penelitian berjumlah 100 orang. Berdasarkan perbedaan jenis kelamin, terdapat $46 \%$ laki-laki, dan $54 \%$ perempuan. Wisatawan domestik
} 
sebesar 46\%, 28\% berkebangsaan Australia, dan sisanya berkebangsaan lain. Pengunjung mahasiswa sebesar $28 \%$, $18 \%$ adalah pensiunan, dan $46 \%$ adalah pekerja di berbagai sektor. Hasil analisis structural equation modelling (SEM) membuktikan bahwa faktor pendorong wisatawan tidak berpengaruh nyata terhadap kedatangan wisatawan ke Desa Wisata Blimbingsari. Namun, faktor daya tarik Desa Blimbingsari berpengaruh nyata terhadap kedatangan wisatawan ke desa ini. Pengelolaan Desa Wisata Blimbingsari sebaiknya diarahkan untuk menonjolkan daya tarik desa seperti keunikan desa, aktivitas masyarakat desa, budaya/adat/tradisi, keindahan alam desa, ketersediaan penginapan, kuliner, fasilitas umum, visitor center, jarak dari bandara, jarak dari ibu kota Provinsi Bali, dan ketersediaan transportasi.

Keyword: agrowisata, desa wisata, faktor pendorong, faktor penarik, motivasi berwisata, daya tarik wisata, aktivitas wisata.

\section{Pendahuluan}

abupaten Jembrana adalah salah satu dari sembilan kabupaten
dan kota yang ada di Propinsi Bali yang terletak di bagian barat pulau Bali, dan memiliki luas wilayah sekitar $841.800 \mathrm{~km}^{2}$ atau 14,96 \% dari luas wilayah pulau Bali. Secara Administratif, Kabupaten Jembrana terbagi menjadi lima kecamatan, yang terbentang dari barat ke timur yaitu Kecamatan Melaya, Kecamatan Negara, Kecamatan Jembrana, Kecamatan Mendoyo, Kecamatan Pekutatan (Pemkab Jembrana, 2016). Hampir tiap daerah kecamatan memiliki daya tarik wisata, baik yang belum, sedang, dan sudah dikembangkan.

Berkaitan dengan potensi pariwisata, Kabupaten Jembrana memiliki beberapa daya tarik wisata yang cukup menarik dan sebagian besar berupa daya tarik alam berupa pantai. Daya tarik wisata yang telah ditetapkan oleh Pemerintah Daerah Kabupaten Jembrana sebagai daya tarik wisata adalah seperti pada Tabel 1.1 berikut ini:

\section{Tabel 1.1 Daftar Daya Tarik Wisata Kabupaten Jembrana}




\begin{tabular}{|c|c|c|c|c|}
\hline No & Nama daya tarik wisata & Jenis & Lokasi desa & Kecamatan \\
\hline 1 & Bunut Bolong & Alam & Manggissari & Pekutatan \\
\hline 2 & Pantai Medewi & Alam & Medewi & Pekutatan \\
\hline 3 & Pantai Delodbrawah & Alam & $\begin{array}{l}\text { Delod- } \\
\text { brawah }\end{array}$ & Mendoyo \\
\hline 4 & Rambut Siwi & $\begin{array}{l}\text { Alam dan } \\
\text { Sepiritual }\end{array}$ & $\begin{array}{l}\text { Yeh Embang } \\
\text { Kangin }\end{array}$ & Mendoyo \\
\hline 5 & Perancak & $\begin{array}{l}\text { Alam dan } \\
\text { Sepiritual }\end{array}$ & Perancak & Negara \\
\hline 6 & Pantai Baluk Rening & Alam & Baluk & Negara \\
\hline 7 & Pantai Candikusuma & Alam & $\begin{array}{l}\text { Candi- } \\
\text { kusuma }\end{array}$ & Melaya \\
\hline 8 & Bendungan Palasari & Buatan & Ekasari & Melaya \\
\hline 9 & Teluk Gilimanuk & Alam & Gilimanuk & Melaya \\
\hline 10 & $\begin{array}{l}\text { Museum Manusia Purba } \\
\text { Situs Gilimanuk }\end{array}$ & Buatan & Gilimanuk & Melaya \\
\hline 11 & Pantai Pekutatan & Alam & Pekutatan & Pekutatan \\
\hline 12 & Pantai Pengeragoan & Alam & $\begin{array}{l}\text { Penger- } \\
\text { agoan }\end{array}$ & Pekutatan \\
\hline 13 & Pantai Gumbrih & Alam & Gumbrih & Pekutatan \\
\hline 14 & $\begin{array}{l}\text { Desa Wisata } \\
\text { Sangkaragung }\end{array}$ & Minat khusus & $\begin{array}{l}\text { Sangkara- } \\
\text { gung }\end{array}$ & Negara \\
\hline 15 & Rest Area Rambut Siwi & Buatan & $\begin{array}{l}\text { Yeh Embang } \\
\text { Kangin }\end{array}$ & Mendoyo \\
\hline 16 & Pantai Pangyangan & Alam & Pangyangan & Pekutatan \\
\hline 17 & Air Terjun Juwuk Manis & Alam & $\begin{array}{l}\text { Juwuk } \\
\text { Manis }\end{array}$ & Pekutatan \\
\hline 18 & Wisata Air Gumbrih & Alam & Gumbrih & Pekutatan \\
\hline 19 & $\begin{array}{l}\text { Air Terjun Yeh Embang } \\
\text { Kangin }\end{array}$ & Alam & $\begin{array}{l}\text { Yehembang } \\
\text { Kangin }\end{array}$ & Mendoyo \\
\hline 20 & $\begin{array}{l}\text { Makam Tua ( Buyut } \\
\text { Lebai ) }\end{array}$ & Buatan & $\begin{array}{l}\text { Loloan Ba- } \\
\text { rat }\end{array}$ & Negara \\
\hline 21 & $\begin{array}{l}\text { Rumah Panggung } \\
\text { Peninggalan Suku Bugis }\end{array}$ & Buatan & $\begin{array}{l}\text { Loloan Ba- } \\
\text { rat }\end{array}$ & Negara \\
\hline 22 & Bendungan Benel & Buatan & Benel & Melaya \\
\hline 23 & Monumen Lintas Laut & Buatan & Gilimanuk & Melaya \\
\hline 24 & $\begin{array}{l}\text { Taman Nasional Bali } \\
\text { Barat }\end{array}$ & Alam & Gilimanuk & Melaya \\
\hline 25 & Karang Sewu & Alam & Gilimanuk & Melaya \\
\hline 26 & Desa Wisata Blimbingsari & Buatan & $\begin{array}{l}\text { Blimbing } \\
\text { Sari }\end{array}$ & Melaya \\
\hline
\end{tabular}

Sumber: Pemkab Jembrana (2016)

Walaupun Kabupaten Jembrana telah memiliki 26 daya 
tarik wisata, namun pengembangan sektor pariwisata Jembrana masih mengalami beberapa kendala. Kendala yang cukup berat bagi Jembrana adalah jarak yang cukup jauh dari dari pusat Kota Denpasar sebagai ibukota Provinsi Bali. Wisatawan yang telah berkunjung ke Kabupaten Jembrana tentunya memiliki beberapa motivasi yang mendorong mereka berkunjunjung, dan tentunya daya tarik wisata yang mereka kunjungi memiliki keunikan yang dapat menarik mereka untuk berwisata. Menurut Fandeli, (2001) motivasi berwisata merupakan faktor pendorong dari dalam diri seseorang untuk melakukan perjalanan wisata dan faktor penarik seseorang untuk melakukan perjalanan wisata. Faktor penarik merupakan daya tarik dari sebuah destinasi wisata. Mengetahui motivasi perjalanan wisata dapat menentukan faktor-faktor yang mendorong dan faktor-faktor yang menarik seseorang untuk melakukan perjalanan wisata ke suatu destinasi wisata. Begitu juga menurut Pitana (2005) motivasi merupakan hal yang mendasar dalam studi tentang pariwisata, sebab motivasi merupakan pemicu dari proses perjalanan wisata. Motivasi wisata semakin penting untuk diketahui jika dihubungkan dengan pariwisata sebagai fenomena masyarakat dunia, dimana prilaku masyarakat dipengaruhi oleh berbagai motivasinya.

Penelitian ini adalah tentang motivasi wisatawan yang terdiri atas faktor-faktor yang mendorong, dan yang menarik wisatawan berkunjung ke salah satu daya tarik wisata di Jembrana yakni Desa Wisata Blimbingsari, yang bertujuan untuk menentukan faktorfaktor yang mendorong, dan yang menarik wisatawan berkunjung ke Desa Wisata Blimbingsari. Desa Wisata Blimbingsari adalah sebuah desa wisata yang ditetapkan pada 16 Desember 2011 oleh Gubernur Bali dan diresmikan oleh Bupati Jembrana pada tanggal 25 Desember 2011. Desa Wisata Blimbingsari memiliki beberapa keunikan yang dapat menjadi daya tarik bagi wisatawan untuk berkunjung. Keunikan Desa Wisata Blimbingsari di antaranya adalah berbatasan langsung dengan Kawasan Taman Nasional Bali Barat, berpenduduk mayoritas beragama Kristen Protestan, memiliki gedung gereja dengan arsitektur Bali, menyediakan akomodasi wisatawan yang menyatu dengan rumah-rumah penduduk, dan daya tarik lainnya. Desa wisata ini juga memiliki jalinan kerjasama dengan beberapa organisasi gereja di luar negeri seperti di Australia, Jerman, dan Jepang. 
Sejak ditetapkannya sebagai desa wisata, belum dilakukan penelitian yang terkait dengan wisatawan khususnya terkait dengan hal-hal yang mendorong dan menarik wisatawan datang ke Desa Blimbingsasri. Penelitian terkait dengan desa wisata ini, dilakukan oleh Cristina dan Adikampana (2016) namun hanya meneliti tentang strategi pemasaran Desa Wisata Blimbingsari dengan menggunakan pendekatan bauran pemasaran dari perspektif pengelola saja, bukan perspektif wisatawan. Menurutnya, Desa Wisata Blimbingsari masih memiliki kelemahan dibidang promosi, minimnya informasi tentang desa ini, dan masih rendahnya tingkat kunjungan wisatawan ke desa ini. Rendahnya tingkat kunjungan wisatwan, dimungkinkan karena pengelolaan Desa Wisata Blimbingsari masih mengandalkan pengelolaan berdasarkan kebiasaan masyarakat setempat sehingga belum menyentuh secara langsung harapan para wisatawan.

Penelitian tentang faktor-faktor yang mendorong, dan menarik wisatawan berkunjung ke Desa Wisata Blimbingsari diharapkan dapat mengatasi rendahnya tingkat kunjungan wisatawan ke Desa Wisata Blimbingsari. Metode analisis yang digunakan untuk dapat memecahkan masalah tersebut adalah analisis kuantitatif berupa analisis faktor konfirmatori yang lebih dikenal dengan SEM (Structural Equation Modeling), dan dilengkapi dengan analisis kualitatif sebagai penguat terhadap hasil kuantitatif. Penelitian ini diarahkan untuk memberikan kontribusi secara teoritis dan praktis terhadap pengelolaan Desa Wisata yang sesuai dengan harapan wisatawan dan masyarakat lokal.

Berdasarkan pokok permasalahan yang telah dirumuskan, maka tujuan penelitian ini adalah: untuk menentukan faktorfaktor yang mendorong dan menarik wisatawan berkunjung ke Desa Wisata Blimbingsari. Penelitian ini juga diarahkan untuk memberikan kontribusi secara teoritis dan praktis terhadap hubungan antara faktor pendorong terhadap keberlanjutan Desa Wisata Blimbingsari, dan hubungan antara factor penarik terhadap keberlanjutan Desa Wisata Blimbingsari.

\section{Tinjauan pustaka, teori, dan konsep}

Menurut Pitana, (2005) motivasi merupakan hal yang sangat mendasar dalam studi tentang wisatawan dan pariwisata, karena motivasi merupakan pemicu dari proses perjalanan wisata, walau 
motivasi ini acapkali tidak disadari secara penuh oleh wisatawan itu sendiri. Seseorang melakukan perjalanan wisata dimotivasi dan disebabkan oleh beberapa hal. Motivasi-motivasi tersebut dapat dikelompokkan menjadi empat kelompok besar sebagai berikut: (1) motivasi yang bersifat fisik antara lain untuk relaksasi, kesehatan, kenyamanan, berpartisipasi dalam kegiatan olahraga, bersantai dan sebagainya. (2) Motivasi budaya yaitu keinginan untuk mengetahui budaya, adat, tradisi dan kesenian daerah lain. (3) Motivasi yang bersifat sosial, seperti mengunjungi teman dan keluarga, menemui mitra kerja, melakukan hal-hal yang dianggap mendatangkan gengsi, melakukan ziarah, pelarian dari situasi yang membosankan dan seterusnya. (4) Motivasi fantasi yaitu adanya motivasi di daerah lain sesorang akan bisa lepas dari rutinitas keseharian yang menjemukan dan yang memberikan kepuasan psikologis (Pitana, 2005).

Menurut Kester (2013) bahwa agrowisata adalah bagian dari desa wisata dan terkait dengan aktivitas pertanian. Pengembangan agrowisata dapat menjadi aktivitas tambahan bagi para penduduk desa untuk mendapatkan pendapatan tambahan melalui penjualan produk pertanian mapun produk yang terkait dengan kebutuhan wisatawan. Filosopi agrowisata adalah meningkatkan pendapatan kaum tani, dan meningkatkan kualitas alam menjadi hunian yang benar-benar dapat diharapkan sebagai hunian yang berkualitas, memberikan kesempatan masyarakat untuk belajar kehidupan pertanian yang menguntungkan dan ekosistemnya (Lobo et al, 1999). Wilayah agrowisata dapat secara otomatis berfungsi sebagai pasar yang mempertemukan antara para petani sebagai penghasil produk pertanian dengan para wisatawan sebagai penikmat produk. Produk yang dimaksud tidak sebatas yang berwujud seperti buah-buahan atau sayur-sayuran, tetapi dapat berupa jasa misalnya mengukir buah, jasa lokal guide, dan mungkin atraksi tari-tarian para petani lokal yang mengekpresikan kehidupan bertani mereka (Utama, 2007).

Desa wisata adalah rural tourism yang merupakan jenis daya tarik wisata yang terdiri dari keseluruhan pengalaman pedesaan, atraksi alam, tradisi, dan unsur-unsur yang unik yang dapat menarik minat wisatawan (Joshi, 2012). Menurut Giampiccoli dan Kalis (2012), strategi community based-tourism lebih sering 
digunakan dalam pengembangan rural tourism yang didasarkan pada pengembangan masyarakat dengan cara mengandalkan mereka sendiri, pemberdayaan, keberlanjutan, konservasi dan peningkatan budaya untuk meningkatkan mata pencaharian penduduk. Community based-tourism merupakan pariwisata yang dikelola dan dimiliki oleh masyarakat, untuk masyarakat, dengan tujuan agar wisatawan dapat meningkatkan kesadaran mereka dan belajar tentang kehidupan masyarakat lokal serta dapat meningkatkan ekonomi masyarakat lokal (Putri dan Manaf, 2013).

\section{Metode penelitian}

Penelitian ini berlokasi di Desa Wisata Blimbingsari di Kecamatan Melaya. Kabupaten Jembrana, Provinsi Bali. Populasi pada penelitian ini adalah wisatawan yang mengunjungi Desa Wisata Blimbingsari. Jumlah populasi tidak diketahui dengan pasti sehingga untuk menentukan keterwakilan dari anggota sampel, ditentukan berdasarkan teknik sampling non probabilitas. Teknik nonprobabilitas dibenarkan dalam penelitian, sepanjang tidak bertujuan untuk melakukan generalisasi hasil penelitian (Santoso dan Tjiptono, 2001:91).

Sampel pada penelitian ini dipilih berdasarkan teknik sampling purposive yang merupakan salah satu dari teknik sampling non-probabilitas dengan mempertimbangkan jumlah sampel minimal pada analisis SEM yaitu antara 100 hingga 200 sampel. Jumlah sampel penelitian ini adalah sebasar 100 orang. Jumlah tersebut telah dianggap cukup memadai karena sesuai ketentuan minimum kecukupan alat analisis SEM-AMOS. Kondisi seperti ini, memungkinkan penggunaan teknik ML (maksimum likehood) atau GLS (generelaized least squares) (Ferdinand, 2002:48).

Jenis data yang digunakan adalah data kuantitatif dan data kualitatif. Jenis data ini diambil dari sumber data primer yang didapatkan secara langsung dari hasil survei. Data kuantitatif menurut Sudjana (1996) adalah data yang berbentuk bilangan yang dapat dilakukan perhitungan dengan alat bantu statistik atau matematika. Data kualitatif adalah data yang berbentuk transkrip hasil wawancara, komentar para wisatawan, keterangan-keterangan atau kategori yang mengandung makna kualitas dan bukan berbentuk bilangan (Sudjana, 1996) yang tidak dapat dilakukan perhitungan dengan alat bantu statistik atau matematika. 
Penelitian ini menggunakan dua variabel laten eksogen yakni variabel motivasi berwisata dan variabel daya tarik wisata, serta satu variabel laten endogen yakni variabel keberlanjutan agrowisata. Variabel motivasi wisata terdiri atas indikator: (X1.1) beristirahat dan relaksasi, (X1.2) mengunjungi tempat-tempat baru, (X1.3) belajar hal-hal baru, (X1.4) menjauhkan diri dari stress, (X1.5) melarikan diri dari kegiatan sehari- hari, (X1.6) menemui orang-orang dan bersosialisasi, (X1.7) meningkatkan kesehatan, (X1.8) mencoba tantangan/pengalaman dan petualangan, (X1.9) memperkaya intelektualitas, (X1.10) melatih fisik, dan (X1.11) mengunjungi keluarga dan teman-teman.

Variabel daya tarik wisata Desa Wisata Blimbingsari terdiri atas indikator: (X2.1) keunikan desa, (X2.2) areal perkebunan desa, (X2.3)aktivitas masyarakat desa, (X2.4) budaya/adat/tradisi, (X2.5) keindahan alam desa, (X2.6) penginapan, (X2.7) kuliner, (X2.8) fasilitas umum, (X2.9) visitor center, (X2.10) jarak dari bandara, (X2.11) jarak dari ibu kota, (X2.12) ketersediaan transportasi, (X2.13) pelayanan biro perjalanan, (X2.14) pelayanan pramuwisata lokal, dan (X2.15) keterlibatan masyarakat desa. Variabel keberlanjutan Desa Wisata Blimbingsari terdiri atas indikator: (Y1.1) kesediaan merekomendasi teman atau keluarga, (Y1.2) keinginan berkunjung kembali, (Y1.3) dukungan masyarakat lokal, dan (Y1.4) dukungan pemerintah.

Instrumen yang digunakan dalam penelitian ini, daftar pertanyaan tertutup berupa angket penelitian. Jawaban responden dibuat dengan menggunakan skala likert, yaitu dengan rentangan 1 sampai dengan 5 . Tanggapan yang paling positif (sangat setuju) diberi nilai paling tinggi, dan tanggapan paling negatif (sangat tidak setuju) diberi nilai paling rendah.

Analisis data yang digunakan dalam penelitian ini adalah analisis statistik deskriptif, analisis SEM, dan analisis deskriptif kualitatif sebagai pelengkap. Statistik deskripsi adalah analisis yang dilakukan dengan menggambarkan sekumpulan data secara visual, yang dapat dilakukan dalam dua bagian, yaitu deskripsi dengan numerik, teks dan grafik. Setelah survei dilakukan dan sejumlah data didapat, maka dilakukan pengujian hipotesis dengan menggunakan Structural Equation Modelling (SEM). Kelloway (1995:215) mengemukakan model struktur kovarians 
dapat digunakan untuk menguji berbagai model yang kompleks. SEM adalah model statistik yang menjelaskan hubungan diantara sejumlah variabel, dengan menguji struktur dari hubungan diantara variabel-variabel (Hair et al., 2006).

\section{Hasil penelitian dan analisis}

Hasil penelitian dan analisis tentang motivasi wisatawan berkunjung ke Desa Wisata Blimbingsari, Jembrana Bali, dijelaskan sebagai berikut ini:

\section{Gambaran umum desa wisata Blimbingsari}

Desa Wisata Blimbingsari adalah sebuah desa wisata yang ditetapkan pada 16 Desember 2011 oleh Gubernur Bali dan diresmikan oleh Bupati Jembrana pada tanggal 25 Desember 2011. Desa Wisata Blimbingsari secara keseluruhan luasnya 443 ha. Luasan itu memuat di dalamnya tanah pemukiman seluas 55,88 ha $(12,61 \%)$, tanah perkebunan seluas 351,12 ha $(79,26 \%)$, tanah sawah tadah hujan 10 ha $(2,26 \%)$, tanah adat 20 ha $(4,51 \%)$ serta tanah pemerintahan 6 ha $(1,35 \%)$.

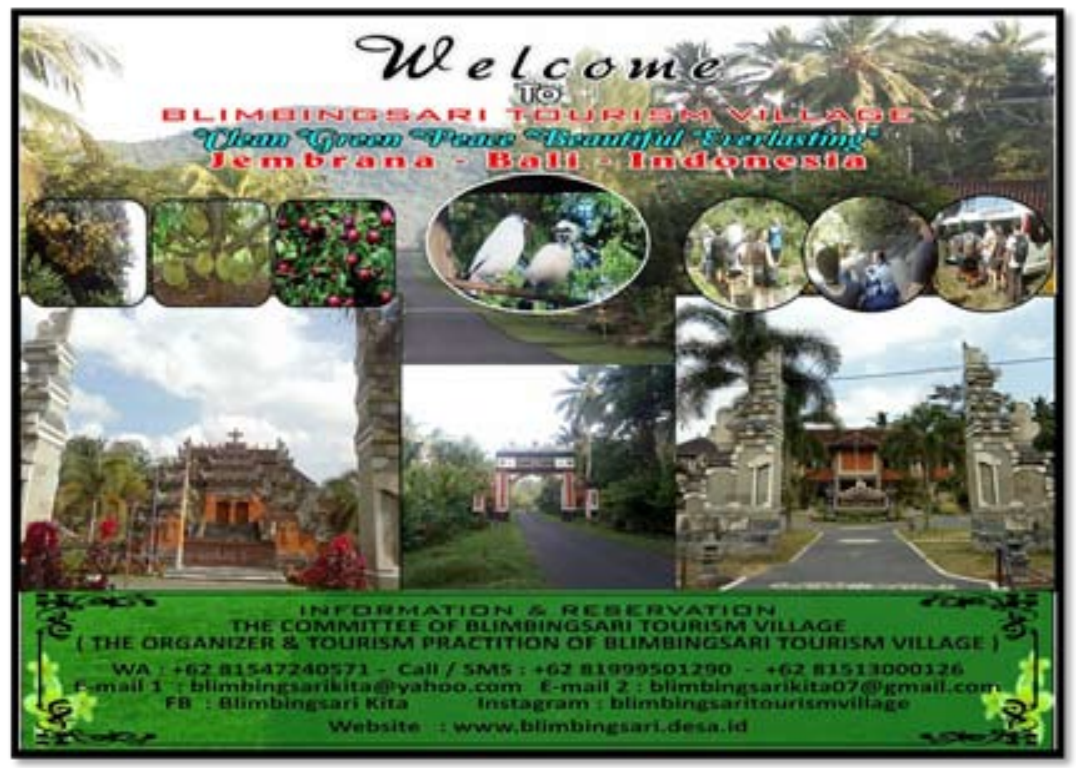

Gambar 4.1 Sebuah Spanduk Penyambut Tamu di Desa Wisata Blimbingsari (Foto-foto Penulis) 
Desa Wisata Blimbingsari mempunyai dua banjar dinas yaitu Banjar Dinas Blimbingsari dan Banjar Dinas Ambyarsari. Banjar Dinas Blimbingsari berlokasi di tengah-tengah Desa Wisata Blimbingsari, berdekatan lapangan alun-alun dan juga Gedung Gereja Pniel Blimbingsari, serta SDK Maranatha Blimbingsari. Banjar Dinas Ambyarsari berlokasi agak dipinggiran Desa Wisata Blimbingsari, kira-kira $2 \mathrm{~km}$ dari Banjar Dinas Blimbingsari. Data kependudukan Kabupaten Jembrana (2016) merinci bahwa jumlah penduduk Desa Wisata Blimbingsari adalah 1.075. Lakilaki berjumlah 518 (48.2\%) dan perempuan berjumlah 557 (51.8\%). Lihat Tabel 4.1 di bawah ini.

Tabel 4.1 Data Agregat Kependudukan Desa Wisata Blimbingsari

\begin{tabular}{|l|r|r|r|}
\hline \multirow{2}{*}{$\begin{array}{c}\text { Kesa/ } \\
\text { Kelurahan }\end{array}$} & Laki-Laki & Perempuan & Jumlah Penduduk \\
\cline { 2 - 4 } & \multicolumn{3}{|c|}{ (Satuan Jiwa) } \\
\hline Gilimanuk & 4.745 & 4.660 & 9.405 \\
\hline Melaya & 5.750 & 5.710 & 11.460 \\
\hline Blimbingsari & $518(48,2 \%)$ & $557(51,8 \%)$ & 1.075 \\
\hline Ekasari & 2.607 & 2.615 & 5.222 \\
\hline Nusasari & 1.860 & 1.901 & 3.761 \\
\hline Warnasari & 1.211 & 1.215 & 2.426 \\
\hline Candikusuma & 2.754 & 2.707 & 5.461 \\
\hline Tuwed & 2.286 & 2.293 & 4.579 \\
\hline Tukadaya & 3.599 & 3.371 & 6.970 \\
\hline Manistutu & 3.909 & 3.819 & 7.728 \\
\hline TOTAL & $29.239(1,7 \%)$ & $28.848(1,9 \%)$ & 58.087 \\
\hline
\end{tabular}

Sumber: Database Kependudukan Kabupaten Jembrana, 2016

Desa Wisata Blimbingsari memiliki kekayaan seni-budaya seperti desa lainnya di wilayah lain di Bali. Kesenian khas yang dimiliki oleh Desa Wisata Blimbingsari adalah tarian yang biasanya diringi oleh gamelan Bali. Bahan musik gamelan ini terbuat dari perunggu dan bagian depan gamelan berisikan hiasan atau ukiran bali dan biasanya memainkan musik ini dilakukan sambil duduk. Seni dan budaya lainnya adalah seni jegog. Seni jegog ini adalah alat musik ciri khas kabupaten Jembrana. Bahan musik jegog ini terbuat dari bambu pilihan yang ukurannya berdiameter $18-20 \mathrm{~cm}$ 
dan bagian depan jegog berisikan hiasan atau ukiran bali. Beda dengan gambelan, seni jegog biasanya memainkan musik jegog ini dilakukan sambil berdiri. Jumlah peserta yang memainkan musik antara gamelan dan jegog hampir sama jumlahnya.

Penduduk Desa Wisata Blimbingsari memiliki pekerjaan yang beragam, diantaranya da yang bertani, dan beternak. Sebagian warga ada yang bekerja sebagai Pegawai Negeri Sipil (PNS), dan berwirausaha. Desa Wisata Blimbingsari memiliki kekayaan senibudaya selayaknya wilayah lain di Bali. Seni dan budaya yang berkembang adalah seni jegog. Seni Jegog ini adalah alat musik ciri khas kabupaten Jembrana. Bahan musik jegog ini terbuat dari bambu pilihan yang ukurannya berdiameter $18-20 \mathrm{~cm}$ (tergantung kebutuhan) dan bagian depan jegog berisikan hiasan atau ukiran bali. Beda dengan gambelan, seni jegog biasanya memainkan musik jegog ini dilakukan sambil berdiri. Jumlah peserta yang memainkan musik antara gamelan dan jegog hampir sama jumlahnya.

\section{Profil responden penelitian}

Responden yang telah berpartisipasi pada penelitian ini berjumlah 100 orang dan telah sesuai dengan kebutuhan jumlah sampel penelitian. Berdasarkan perbedaan jenis kelamin, $46 \%$ pengisi angket penelitian adalah laki-laki, 54\% oleh responden perempuan.

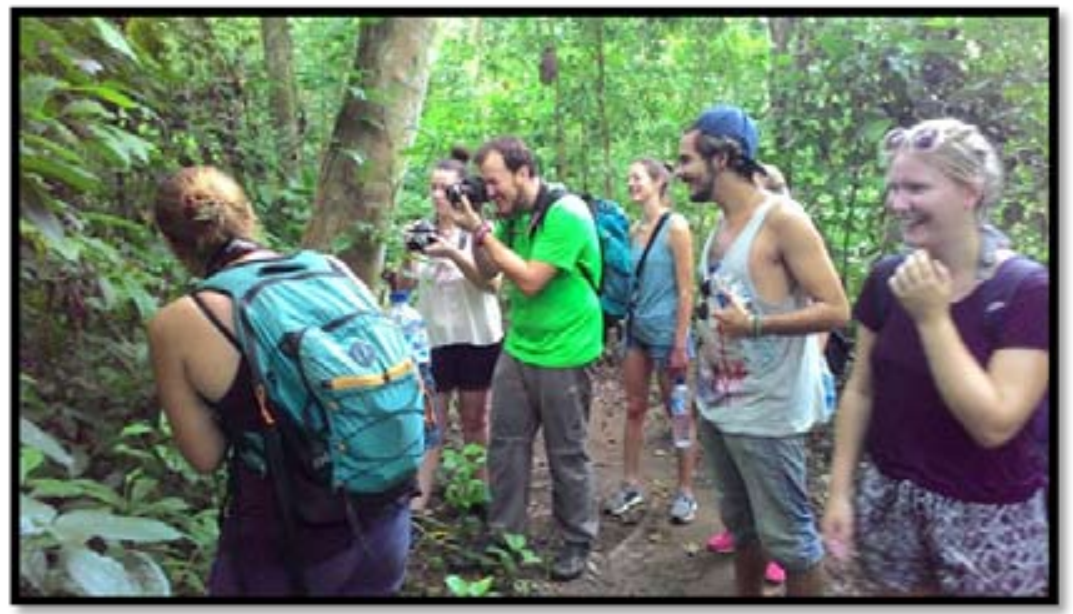

Gambar 4.2 Wisatawan Mancanegara di Desa Wisata Blimbingsari 
Berdasarkan perbedaan kelompok umur, $62 \%$ pengisi angket berumur kurang dari 40 tahun, dan 38\% oleh responden berumur lebih dari 40 tahun.

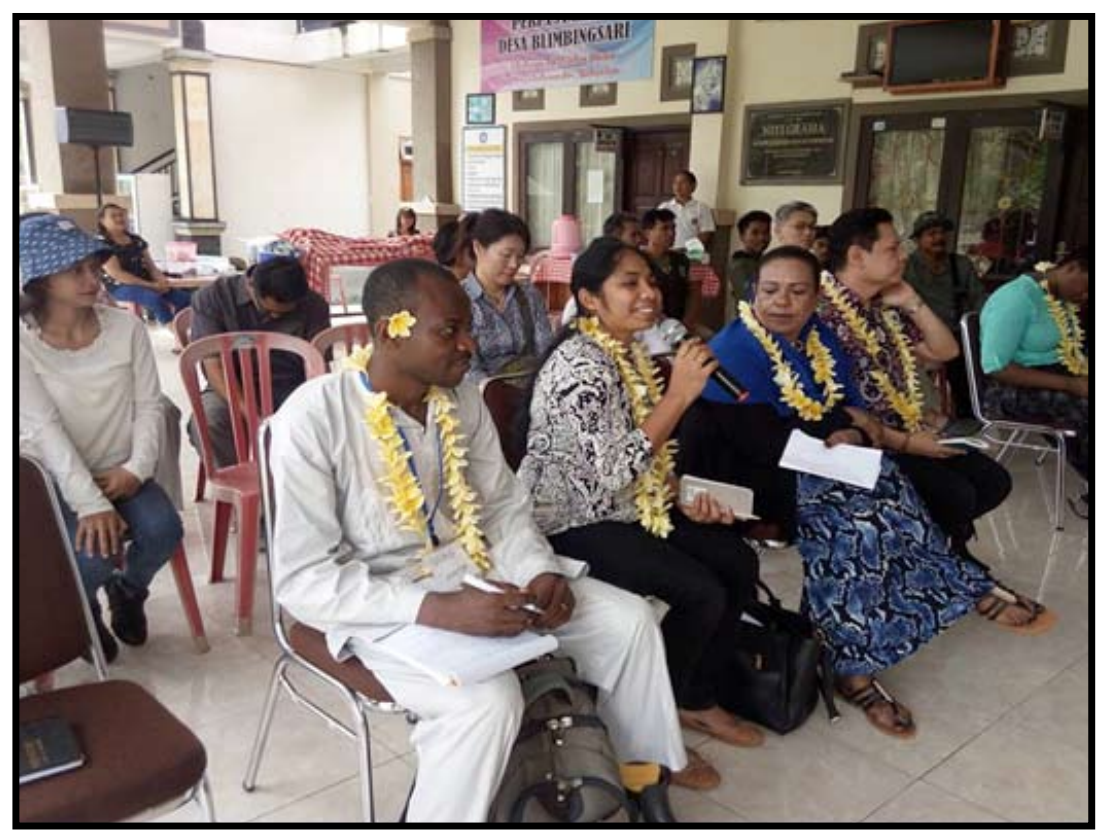

Gambar 4.3 Aktivitas Tracking di Desa Wisata Blimbingsari

Berdasarkan perbedaan kewarganegaraan, dominan responden adalah wisatawan domestik(WNI) $46 \%$, dan $28 \%$ berkebangsaan Australia, sisanya berkebangsaan lainnya. Berdasarkan perbedaan jenis pekerjaan, dominan responden adalah mahasiswa $28 \%$, dan $28 \%$ adalah pensiunan, sisanya pekerjaan lainnya. Berdasarkan pengalaman mereka berkunjung ke Desa Wisata Blimbingsari, dominan responden adalah baru pertama kalinya datang adalah $52 \%$, dan $48 \%$ pernah datang. 


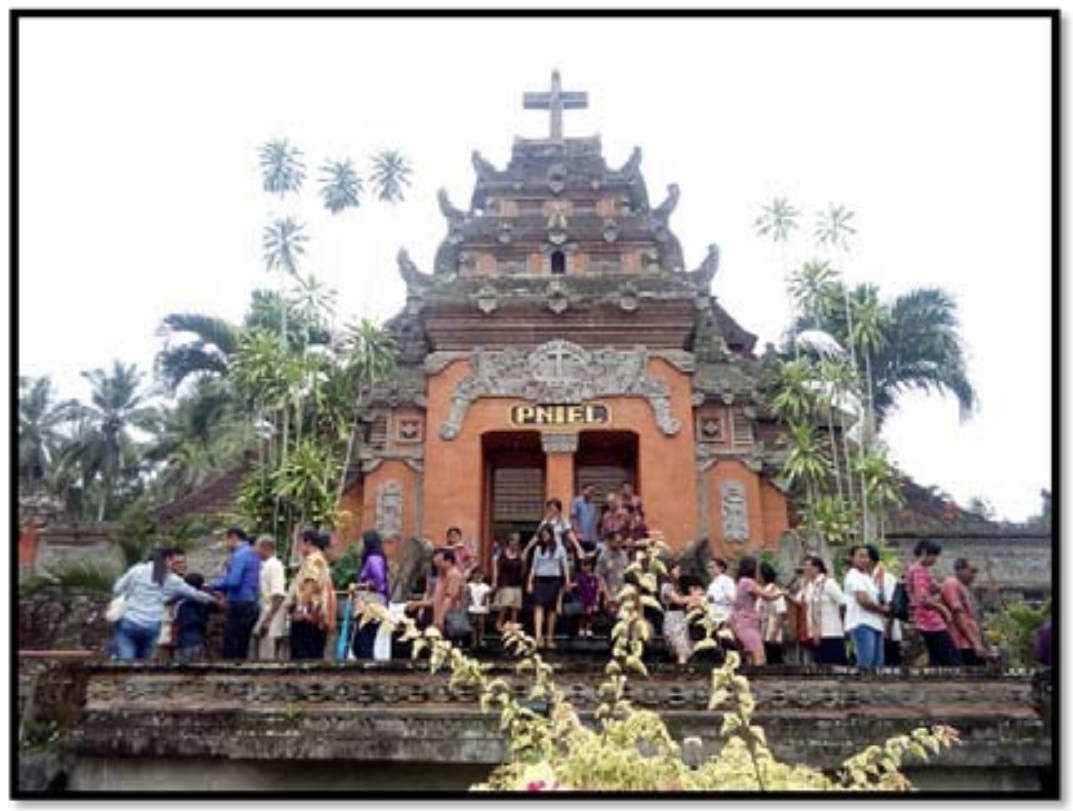

Gambar 4.4 Keunikan Gedung Gereja di Desa Wisata Blimbingsari

\section{Persepsi Wisatawan terhadap Desa Wisata Blimbingsari}

Analisis statistik deskriptif digunakan dalam penelitian ini untuk mengetahui tingkat distribusi responden berdasarkan hasil kuesioner yang dibesar kepada 100 responden dan berhasil ditarik sebesar $100 \%$ (Lihat Tabel 4.2)

\section{Tabel 4.2 Deskriptif Statistik Indikator Penelitian}

\begin{tabular}{|c|c|c|}
\hline Faktor dan Indikator Penelitian & Rata-rata & Keterangan \\
\hline \multicolumn{3}{|l|}{ Faktor Pendorong } \\
\hline 1) Istirahat dan rileksasi & 4,21 & Sangat terdorong \\
\hline 2) Mengunjungi tempat baru & 4,20 & Terdorong \\
\hline 3) Mencari pengalaman & 4,32 & Terdorong \\
\hline 4) Menghindari Stres & 4,27 & Terdorong \\
\hline 5) Keluar dari rutinitas & 4,17 & Terdorong \\
\hline 6) Bersosialisasi & 3,91 & Terdorong \\
\hline 7) Meningkatkan kesehatan & 3,29 & Netral \\
\hline
\end{tabular}




\begin{tabular}{|c|c|c|}
\hline Faktor dan Indikator Penelitian & Rata-rata & Keterangan \\
\hline 8) Petualangan & 3,70 & Terdorong \\
\hline 9) Meningkatkan pengetahuan & 4,26 & Sangat Terdorong \\
\hline 10) Latihan fisik & 4,23 & Sangat Terdorong \\
\hline $\begin{array}{l}\text { 11) Mengunjungi teman dan } \\
\text { sahabat }\end{array}$ & 3,95 & Terdorong \\
\hline \multicolumn{3}{|l|}{ Faktor Penarik } \\
\hline 1) Keunikan desa & 4,21 & Sangat tertarik \\
\hline $\begin{array}{l}\text { 2) Lahan pertanian dan } \\
\text { perkebunan }\end{array}$ & 4,20 & Tertarik \\
\hline 3) Aktivitas masyarakat desa & 4,04 & Tertarik \\
\hline 4) Tradisi dan budaya desa & 3,60 & Tertarik \\
\hline 5) Keindahan alam pedesaan & 4,08 & Tertarik \\
\hline 6) Fasilitas penginapan desa & 3,93 & Tertarik \\
\hline 7) Kuliner desa & 3,52 & Tertarik \\
\hline 8) Fasilitas umum & 3,34 & Netral \\
\hline 9) Pusat informasi wisata desa & 3,34 & Netral \\
\hline 10) Jarak dari bandara & 3,06 & Netral \\
\hline 11) Jarak dari ibukota provinsi & 2,98 & Netral \\
\hline 12) Ketersediaan transportasi & 3,18 & Netral \\
\hline 13) Pelayanan Biro perjalanan wisata & 3,99 & Tertarik \\
\hline 14) Pemandu wisata lokal & 3,81 & Tertarik \\
\hline 15) Keterlibatan masyarakat & 4,28 & Sangat Setuju \\
\hline \multicolumn{3}{|l|}{ Faktor Keberlanjutan Desa Wisata } \\
\hline 1) Niat merekomendasi teman & 4,26 & Sangat Setuju \\
\hline 2) Niat berkunjung kembali & 4,22 & Sangat Setuju \\
\hline 3) Dukungan pemerintah daerah & 3,60 & Setuju \\
\hline $\begin{array}{l}\text { 4) Dukungan dan keterlibatan } \\
\text { masyarakat desa }\end{array}$ & 4,19 & Setuju \\
\hline
\end{tabular}

Catatan: Interval $(1,00-1,80)$ 


\section{Pengujian model teoritis}

Metode estimasi yang dipilih pada penelitian ini adalah Maximum Likelihood Estimates (MLE). Setelah dilakukan pengujian model dengan hanya menyertakan indikator-indikator yang memiliki nilai Standardized Regression Weights lebih besar dari 0,5 maka terbentuklah model yang dinyatakan fit. Hasil modifikasi model seperti Gambar 4.5 berikut:

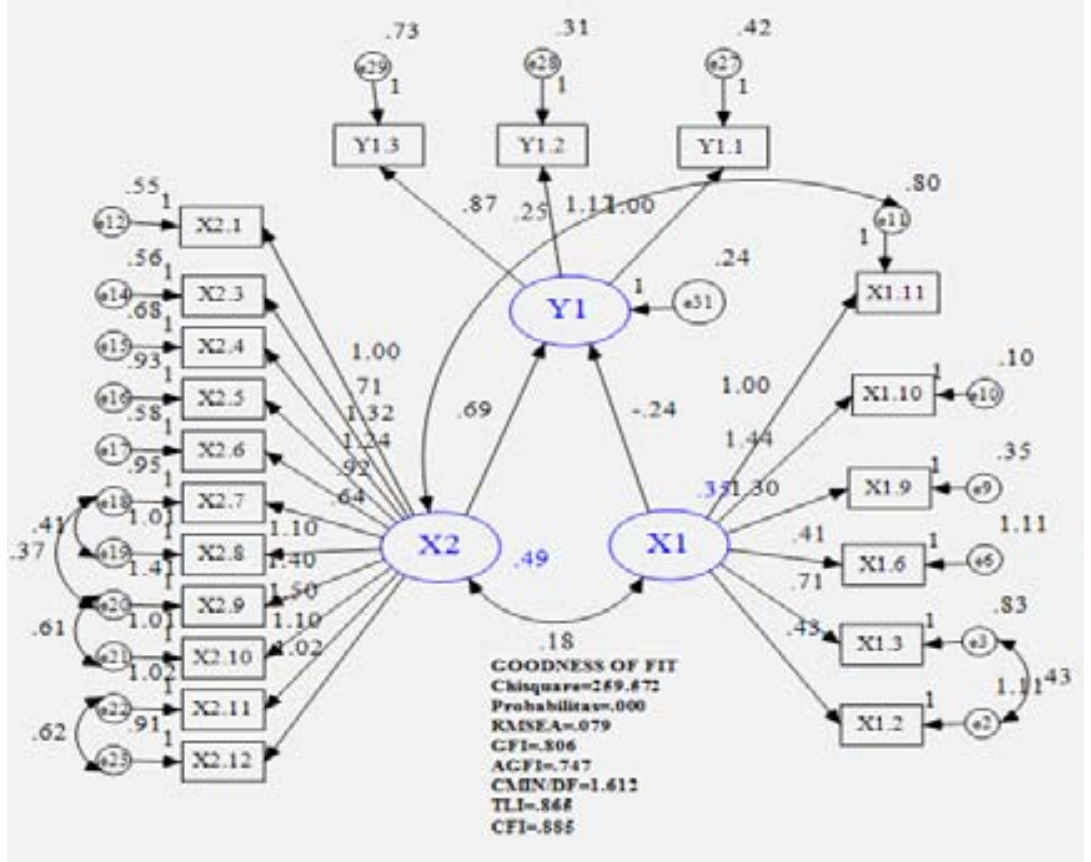

Gambar 4.5 Konstruk Model Desa Wisata Blimbingsari

Dari beberapa kriteria untuk mengukur model yang fit, yakni X2-Chi Square, RMSEA, CMIN/DF, TLI, dan CFI menunjukkan bahwa model dapat dikatakan fit atau disimpulkan bahwa model teoritis sesuai dengan fakta empiris dari penelitian yang telah dilakukan (lihat Tabel 4.3) 
Tabel 4.3 Hasil Modifikasi Model

\begin{tabular}{lccl}
\hline Goodness of Fit Index & Cut off Value & Result & Keputusan \\
\hline X²-Chi Square & Diharapkan Kecil & 259,572 & Fit/Sesuai \\
RMSEA & $\leq 0,08$ & 0,078 & Moderate \\
GFI & $\geq 0,90$ & 0,806 & Kurang Sesuai \\
AGFI & $\geq 0,90$ & 0,747 & Kurang Sesuai \\
CMIN/DF & $\leq 3,00$ & 1,612 & Fit/Sesuai \\
\hline
\end{tabular}

Sumber: Hasil Uji Konstruk Modifikasi Model

Setelah semua asumsi dapat dipenuhi, maka selanjutnya dilakukan pengujian hipotesis sebagaimana diajukan pada bagian sebelumnya. Pengujian dua hipotesis penelitian ini dilakukan sebagai berikut.

\section{Tabel 4.4 Bobot Regresi Hubungan Struktural}

\begin{tabular}{|c|c|c|c|c|c|c|}
\hline No & & ubungan & SRW & C.R. & P-Value & Keputusan \\
\hline 1 & $\begin{array}{l}\text { Y (Keber- } \\
\text { lanjutan) }\end{array}$ & $\begin{array}{ll}\leftarrow \quad & \text { X.1 (Faktor } \\
& \text { Pendorong) }\end{array}$ & $-0,218$ & $-1,764$ & 0,078 & $\begin{array}{l}\text { Tidak } \\
\text { Signifikan }\end{array}$ \\
\hline 2 & $\begin{array}{l}\text { Y (Keber- } \\
\text { lanjutan) }\end{array}$ & $\leftarrow \begin{array}{l}\text { X.2 (Faktor } \\
\text { Penarik) }\end{array}$ & 0,732 & 4,452 & $* * *$ & Signifikan \\
\hline
\end{tabular}

Sumber: Hasil Uji Konstruk Modifikasi Model, SRW = Standardized Regression Weights

Faktor pendorong wisatawan berkunjung ke desa wisata Blimbingsari

Parameter estimasi untuk pengujian pengaruh $\left(X_{1}\right)$ motivasi terhadap $\left(Y_{1}\right)$ keberlanjutan Desa Wisata Blimbingsari ditunjukkan oleh nilai CR (critical ratio) sebesar -1,764 dan dengan probabilitas sebesar 0,078. Kedua nilai tersebut tidak memenuhi syarat untuk penerimaan $H_{1}$ yaitu nilai $C R$ yang lebih kecil dari 1,96 dan probabilitas yang lebih besar dari 0,05. Kesimpulannya adalah $\left(X_{1}\right)$ Faktor motivasi tidak berpengaruh signifikan terhadap $\left(Y_{1}\right)$ Keberlanjutan Desa Wisata Blimbingsari. Hubungan teoritis kedua variabel tersebut dinyatakan tidak sesuai fakta empiris sehingga hubungan yang terjadi dapat dikatakan tidak signifikan. 
Kesimpulan lain yang dapat dinyatakan adalah faktor motivasi yang dimilikioleh wisatawan belum mampu mengarahkan tujuan kunjungannya ke Desa Wisata Blimbingsari, dan diduga faktor lainlah yang menyebabkan para wisatawan mengarahkan kunjungannya ke Desa Wisata Blimbingsari.

\section{Faktor penarik wisatawan berkunjung ke desa wisata Blimbingsari}

Parameter estimasi untuk pengujian pengaruh $\left(\mathrm{X}_{2}\right)$ Faktor Penarik terhadap $\left(Y_{1}\right)$ Keberlanjutan Desa Wisata Blimbingsari ditunjukkan oleh nilai CR (critical ratio) sebesar 4,452dan dengan probabilitas sebesar ${ }^{* * *}$. Kedua nilai tersebut telah memenuhi syarat untuk penerimaan $\mathrm{H}_{1}$ yaitu nilai $\mathrm{CR}$ yang lebih besar dari 1,96 dan probabilitas yang lebih kecil dari 0,05. Kesimpulannya adalah $\left(\mathrm{X}_{2}\right)$ Faktor Daya Tarik Desa Wisata Blimbingsari berpengaruh signifikan terhadap $\left(Y_{1}\right)$ keberlanjutan Desa Wisata Blimbingsari. Hubungan teoritis kedua variabel tersebut dinyatakan telah sesuai dengan fakta empiris sehingga hubungan yang terjadi dapat dikatakan signifikan. Kesimpulan lain yang dapat dinyatakan adalah faktor daya tarikyang dimiliki oleh Desa Wisata Blimbingsari telah mampu mengarahkan tujuan wisatawan berwisata ke Desa tersebut.

\section{Faktor keberlanjutan desa wisata Blimbingsari}

Secara empiris, keberlanjutan desa wisata Blimbingsari ditentukan oleh tiga indikator penting. Tiga indikator tersebut adalah kesediaan para pengunjung untuk merekomendasi teman atau keluarganya agar bersedia berwisata ke daya tarik wisata Blimbingsari, adanya niat atau keinginan para wisatawan untuk berkunjung kembali di masa yang akan datang, dan yang paling penting adanya dukungan masyarakat lokal dalam mengelolaan Desa Wisata.

\section{Hubungan faktor pendorong dan penarik terhadap keberlanjutan desa wisata Blimbingsari}

Hubungan faktor pendorong dan penarik terhadap keberlanjutan Desa Wisata Blimbingsari dapat dijelaskan sebagai berikut ini: Indikator-indikator dari faktor pendorong wisatawan berkunjung ke Desa Wisata Blimbingsari dapat dijadikan alasan yang kuat untuk melakukan pengembangan dan inovasi Desa Wisata Blimbingsari (Lihat Gambar 4.6) 


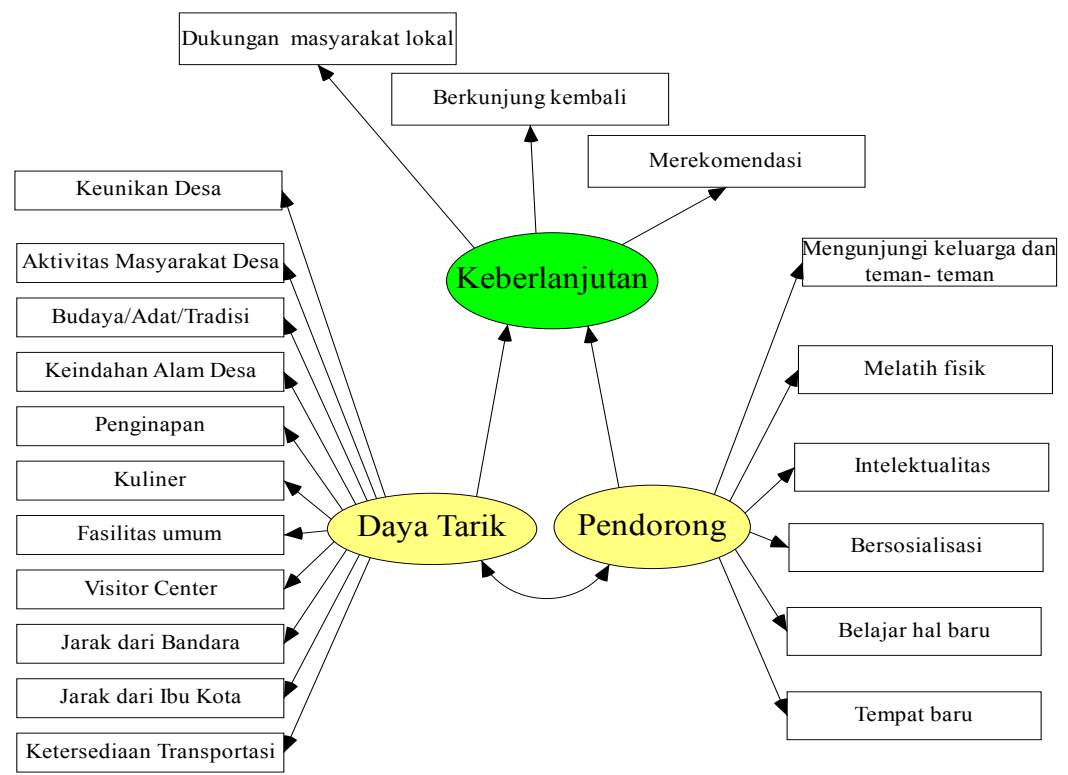

\section{Gambar 4.6 Hubungan Faktor Pendorong dan Penarik terhadap Keberlanjutan Desa Wisata Blimbingsari}

Terdapat enam indikator yang mendorong wisatawan datang ke desa tersebut, diantaranya adalah sebagai berikut: (1) mengunjungi tempat-tempatbaru, (2) belajar dan mengalami hal-hal baru, (3) menemui orang-orang dan bersosialisasi, (4) memperkaya intelektualitas, (5) melatih fisik, dan (6) mengunjungi keluarga dan teman- teman. Indikator tersebut menunjukkan bahwa fasilitas atau daya tarik wisata buatan (man made) dapat dikembangkan untuk memenuhi keinginan para pengunjung/

Indikator-indikator dari faktor penarik wisatawan berkunjung ke Desa Wisata Blimbingsari dapat dijadikan alasan yang kuat juga untuk melakukan pengelolaan dan pengembangan Desa Wisata Blimbingsari yang lebih baik. Indikator-indikator tersebut adalah keunikan desa, aktivitas masyarakat desa, budaya/adat/tradisi, keindahan alam desa, ketersediaan penginapan, kuliner, fasilitas umum, visitor center, jarak dari bandara, jarak dari ibu kota, dan ketersediaan transportasi. 
Indikator-indikator dari faktor keberlanjutan Desa Wisata Blimbingsari dapatdijadikanalasanyangkuatjugauntukmelakukan pengelolaan dan pengembangan Desa Wisata Blimbingsari di masa yang akan datang adalah kesediaan merekomendasi teman atau keluarga, keinginan berkunjung kembali, dandukungan masyarakat lokal.

\section{Penutup}

Hasil pengujian hubungan antara faktor pendorong dan penarik terhadap keberlanjutan Desa Wisata Blimbingsari membuktikan bahwafaktorpendorongwisatawantidakberkorelasinyata terhadap keberlanjutan Desa Wisata Blimbingsari, namun factor penarik (daya tarik) Desa Wisata Blimbingsari yang justru berkorelasi nyata terhadap keberlanjutan Desa Wisata Blimbingsari.

Wisatawan yang datang ke Desa Wisata Blimbingsari termotivasi untuk (1) mengunjungi tempat-tempat baru, (2) untuk belajar dan mengalami hal-hal baru, (3) menemui orang-orang dan bersosialisasi, (4) alasan untuk memperkaya intelektualitas, (5) melatih fisik, dan (6) motif mengunjungikeluarga dan teman-teman. Daya Tarik Desa Wisata Blimbingsari adalah (1) keunikan desa, (2) aktivitas masyarakat desa, (3) budaya/adat/tradisi, (4) keindahan alam desa, (5) tersedianya penginapan, (6) tersedianya kuliner, (7) fasilitas umum. Empat Indikator lainnya seperti (1) visitor center yang masih terbatas, (2) jarak dari bandara yang cukup jauh yakni $120 \mathrm{~km}$, (3) jarak dari ibu kota yang cukup jauh yakni kisaran 3 jam lama perjalanan, dan (4) ketersediaan transportasi yang menuju ke desa wisata Blimbingsari. Empat indikator tersebut merupakan indikator yang menjadi kelemahan bagi desa wisata blimbingsari. Keberlanjutan Desa Wisata Blimbingsari adalah (1) kesediaan merekomendasi teman atau keluarga, (2) keinginan berkunjung kembali, dan (3) dukungan masyarakat lokal.

Pengelolaan Desa Wisata Blimbingsari sebaiknya diarahkan untuk menonjolkan daya tarik desa daripada variabel lainnya dengan cara membuat usaha-usaha yang dapat meningkatkan penampilan desa. Usaha usaha yang dapat dilakukan untuk merespon faktor penarik wisatawan berkunjung ke Desa Wisata Blimbingsari adalah dengan tetap melestarikan tradisi dan budaya 
yang diaktualisasi dengan kondisi masyarakat setempat, melatih masyarakat dengan ketrampilan kepariwisataan. Usaha-usaha untuk mengatasi kelemahan yang ada saat ini adalah melatih komite pariwisata dengan ketrampilan administrasi, database, dan internet, serta menawarkan paket wisata menginap di Desa Wisata Blimbingsari, misalnya paket tiga malam dengan jadual kegiatan yang terkonsentrasi di Desa Blimbingsari.

\section{Ucapan terima kasih}

Penulis mengucapkan terimakasih yang sebesar-besarnya kepada Kementerian RISTEKDIKTI atas pendanaan penelitian ini melalui Skema Penelitian Produk Terapan (PPT) tahun anggaran 2016 sehingga dapat dilaksanakan dengan baik dan menghasilkan publikasi ilmiah. Terima kasih juga kepada dua reviewer anonim Jurnal Kajian Bali atas saran dan masukannya yang berguna untuk penyempurnaan artikel ini.

\section{Daftar pustaka}

Ratu, C., Adikampana, I., 2016. “Strategi Pemasaran Desa Wisata Blimbingsari Kabupaten Jembrana". Jurnal Destinasi Pariwisata: 4 (1), pp.60-67, Universitas Udayana, Denpasar.

Kependudukan dan Demografi Kecamatan Melaya. 2016. “Database Kependudukan Kabupaten Jembrana. Negara, Bali". Diakses dari http://jembranakab.go.id/ pada tanggal 20 Juni 2016.

Fandeli, Chafid. 2001. Basics of Tourism Management of Natural (Dasar-dasar Managemen Kepariwisataan Alam). Yogyakarta: Liberty.

Ferdinand, Agusty. 2002. Structural Equation Modeling Dalam Penelitian Manajemen. Semarang: BP UNDIP.

Ghozali, Imam. 2005. Aplikasi analisis multivariate dengan program SPSS. Semarang: Badan Penerbit Universitas Diponegoro.

Hair, Joseph F.; William C. Black; Barry J. Babin; Raplh E. Anderson; and Ronald L. Tatham. 2006. Multivariate Data Analysis, 6th ed. Upper Saddle River, New Jersey: Pearson Education, Inc. 
Indonesian Agricultural Department. 2005. “Agrowisata Meningkatkan Pendapatan Petani". Diakses dari http://database.deptan.go.id pada 12 November 2006.

Giampiccoli, A., Kalis, J.H., 2012. "Community-based tourism and local culture: the case of the amaMpondo". PASOS Revista de Tourism y Patrimonio Cultural, 10(1), pp.173-188, South Africa : Nort- West University and Walter Sisulu University.

Joshi, P.V., 2012. "A stakeholders networking for sustainable rural tourism development in Konkan Region of Maharashtra State India:". Golden Research Thoughts, 1(3), pp.1-4, Narayangaon: College of Agricultural Economics and Marketing Hall.

Kelloway, E.K., 1995. "Structural equation modelling in perspective". Journal of Organizational Behavior, 16(3), pp.215-224.

Kester, J.G. 2013. "International Tourism Results and Prospects for 2013". United Nations World Tourism Organization (UNWTO), Madrid.

Lobo, R., Goldman, G., Jolly, D., Wallace, B., Schrader, W.L. and Parker, S., 1999. "Agritourism benefits agriculture in San Diego county". California Agriculture, 53(6), pp.20-24.

Pitana, I.G. and Gayatri, P.G., 2005. Sosiologi pariwisata: kajian sosiologis terhadap struktur, sistem, dan dampak-dampak pariwisata. Yogyakarta: Andi.

Putri, Hemas Prabawati Jakti., Manaf, Asnawi. 2013. "Faktor - faktor Keberhasilan Pengembangan Desa Wisata di Dataran Tinggi Dieng". Jurnal Teknik PWK Volume 2 Nomor 3 2013: Undip, Semarang.

Santoso, S., Tjiptono, F., 2001. Riset Pemasaran konsep dan Aplikasi dengan SPSS. Jakarta: PT. Elex Media Komputindo,

Solimun. 2002. Structural equation modeling (SEM) Lisrel dan Amos. Malang: Fakultas MIPA Universitas Brawijaya.

Solomon, M,. 1996. Consumer Behavior, 3rd edition, Engelwood Cliffs: Prentice-Hall,

Sudjana, N., 1996. Metode Penelitian. Bandung: Tarsito.

Utama, I.G.B.R. 2007. Agrotourism as an alternative form of tourism in Bali Indonesia. Germany : Scholar-Press 
Utama, I.G.B.R., 2016. “Keunikan Budaya dan Keindahan Alam sebagai Citra Destinasi Bali menurut Wisatawan Australia Lanjut Usia". Jurnal Kajian Bali, 6. Universitas Udayana, Denpasar.

Utama, I.G.B.R. 2016. Metodologi Penelitian Pariwisata dan Hospitalitas: dilengkapi studi kasus penelitian. Denpasar: Pustaka Larasan.

Utama, I.G.B.R., 2016. Pengantar Industri Pariwisata. Yogyakarta: Deepublish. 